Article

\title{
Evaluation of Multifarious Plant Growth Promoting Trials of Yeast Isolated from the Soil of Assam Tea (Camellia sinensis var. assamica) Plantations in Northern Thailand
}

\author{
Jaturong Kumla ${ }^{1,2, * \mathbb{D}}$, Supakorn Nundaeng ${ }^{2}$, Nakarin Suwannarach ${ }^{1,2} \mathbb{D}$ and \\ Saisamorn Lumyong 1,2,3 \\ 1 Research Center of Microbial Diversity and Sustainable Utilization, Chiang Mai University, \\ Chiang Mai 50200, Thailand; suwan.462@gmail.com (N.S.); scboi009@gmail.com (S.L.) \\ 2 Department of Biology, Faculty of Science, Chiang Mai University, Chiang Mai 50200, Thailand; \\ Supakorn.ning@gmail.com \\ 3 Academy of Science, The Royal Society of Thailand, Bangkok 10300, Thailand \\ * Correspondence: jaturong_yai@hotmail.com; Tel.: +66-87-1926-527
}

Received: 30 June 2020; Accepted: 28 July 2020; Published: 1 August 2020

\begin{abstract}
Some soil microorganisms, especially bacteria and mycorrhizal fungi, play a role in the promotion of plant growth. However, plant growth promotion involving yeasts in soil has not yet been extensively investigated. This study aimed to isolate and identify yeast strains obtained from soils of the Assam tea plant (Camellia sinensis var. assamica) in northern Thailand and to investigate their plant growth promoting capabilities. A total of 42 yeast strains were obtained and identified by analysis of the D1/D2 domain of the large subunit ribosomal RNA gene. We identified 35 strains of six species belonging to the phylum Ascomycota, namely Aureobasidium melanogenum, Kazachstania aquatica, Saturnispora diversa, Saturnispora sekii, Schwanniomyces pseudopolymorphus and Wickerhamomyces anomalus, and six species were determined to belong to the phylum Basidiomycota, namely Apiotrichum scarabaeorum, Curvibasidium pallidicorallinum, Papiliotrema laurentii, Rhodosporidiobolus ruineniae, Trichosporon asahii and Trichosporon coremiiforme. Seven strains were representative of potential new species and belonged to the genera Galactomyces and Wickerhamomyces. A total of 28 strains were found to produce indole-3-acetic acid (IAA) in a range of 2.12 to $37.32 \mathrm{mg} / \mathrm{L}$, with the highest amount of IAA produced by R. ruineniae SDBR-CMU-S1-03. All yeast strains were positive in terms of ammonia production, and only eight strains were positive for siderophore production. Two yeast species, P. laurentii and $W$. anomalus, were able to solubilize the insoluble form of calcium and zinc. The ability to produce amylase, endogulcanase, lipase, pectinase, protease and xylanase was dependent upon the yeast species and strain involved.
\end{abstract}

Keywords: soil yeast; plant growth promoting; Assam tea plant; Thailand

\section{Introduction}

The Assam tea plant (Camellia sinensis var. assamica) is a non-alcoholic caffeine-containing beverage crop that is primarily cultivated for its leaf [1,2]. This tea plant is native to East and Southeast Asia, but it is currently being cultivated worldwide in various tropical and subtropical regions [2,3]. The Assam tea plant is commonly grown in higher agricultural areas in northern Thailand at elevations of 450-1500 m above sea level. These areas include the provinces of Chiang Mai, Chiang Rai, Lampang, Mae Hong Son, Nan, Phayao and Phrae [4,5]. Normally, Assam tea leaves have been used to make black tea and "Miang", a traditional unique fermented food of northern Thailand [5-7]. Soil degradation and the 
substantial quality of the tea have been associated with the long-term monoculture of tea plantations [8]. Chemical-based fertilizers are commonly used for the promotion of tea plant growth, which are also known to cause environmental pollution, soil acidification, heavy metal pollution, soil compaction and changes in soil microbial populations. These fertilizers are also known to be hazardous to the health of farmers as well [8-10]. Many research studies have been done on the effects of chemical fertilization in terms of both tea yield and quality [11-13]. For this reason, researchers have been interested in replacing chemical-based fertilizers with various techniques that involve the application of beneficial microorganisms, especially plant growth promoting microorganisms (PGPMs) that can support the sustainability of the agricultural industry and the environment [14-16].

PGPMs have been defined as microorganisms (fungi, bacteria, actinomycetes and yeasts) that can enhance plant growth, improve plant nutrient uptake, induce systematic resistance and increase stress tolerance through one of the following mechanisms nitrogen fixation, solubilization of insoluble minerals, exopolysaccharide secretion, biocontrol activity, phytohormone production, siderophores production etc. [17-19]. PGPMs are usually 1-2\% of the total microorganisms that live in/on plants, the soil and the rhizosphere zone. These microorganisms have been categorized as free living and as having a symbiotic association with the plants $[16,18]$. PGPMs have been isolated from the endospheres, phyllospheres and rhizospheres of many plant species [20-22]. Yeasts are microorganisms that they are widely dispersed and commonly found on plant leaves, flowers, fruits and in the soil [23-25]. Some yeast species (Aureobasidium pullulans, Candida tropicalis, Moesziomyces aphidis and Rhodotorula mucilaginosa) have the ability to promote plant growth and have been identified as PGPMs [26-29]. Although, there have been relatively few studies on plant growth promoting yeasts obtained from soils. The objective of our study was to isolate the yeast strains obtained from the rhizosphere soil of Assam tea plantations located in northern Thailand, to identify them and to study their characteristics in terms of their plant growth promoting abilities (production of indole-3-acetic acid (IAA), siderophore, ammonia and extracellular enzymes, and the solubilization of insoluble minerals). The knowledge gained from this research study can be used to develop plant growth promoting yeast as a bioinoculant, which may replace the chemical-based fertilizers that are currently being used.

\section{Materials and Methods}

\subsection{Sample Collection}

Soil samples were collected from three Assam tea plantations (Camellia sinensis var. assamica) in Chiang Mai Province (Thep Sadej, Doi Saket District, $18^{\circ} 58^{\prime} 3^{\prime \prime}$ N 99 21'58” E), and Nan Province

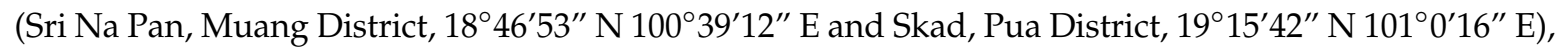
of northern Thailand during a one-year period from 2016 to 2017 (Figure 1). All collection sites were known to be monocultures of Assam tea. Rhizosphere soil samples of five plants were randomly collected at each site. Soil samples were aseptically collected at a depth of $5-10 \mathrm{~cm}$ from the surface soil in the rhizosphere zone using a stainless steel spade. The soil samples were kept in sterile plastic bags and carried to the laboratory on ice within $48 \mathrm{~h}$ of being collected. All collected soil samples were processed for the isolation of yeast immediately after reaching the laboratory. Type, $\mathrm{pH}$ value and electrical conductivity (EC) of the soil samples were determined at the Soil Science Laboratory, Faculty of Agriculture, Chiang Mai University, Thailand. The type, $\mathrm{pH}$ value and EC of the soil samples from each collection site are shown in Table 1. 


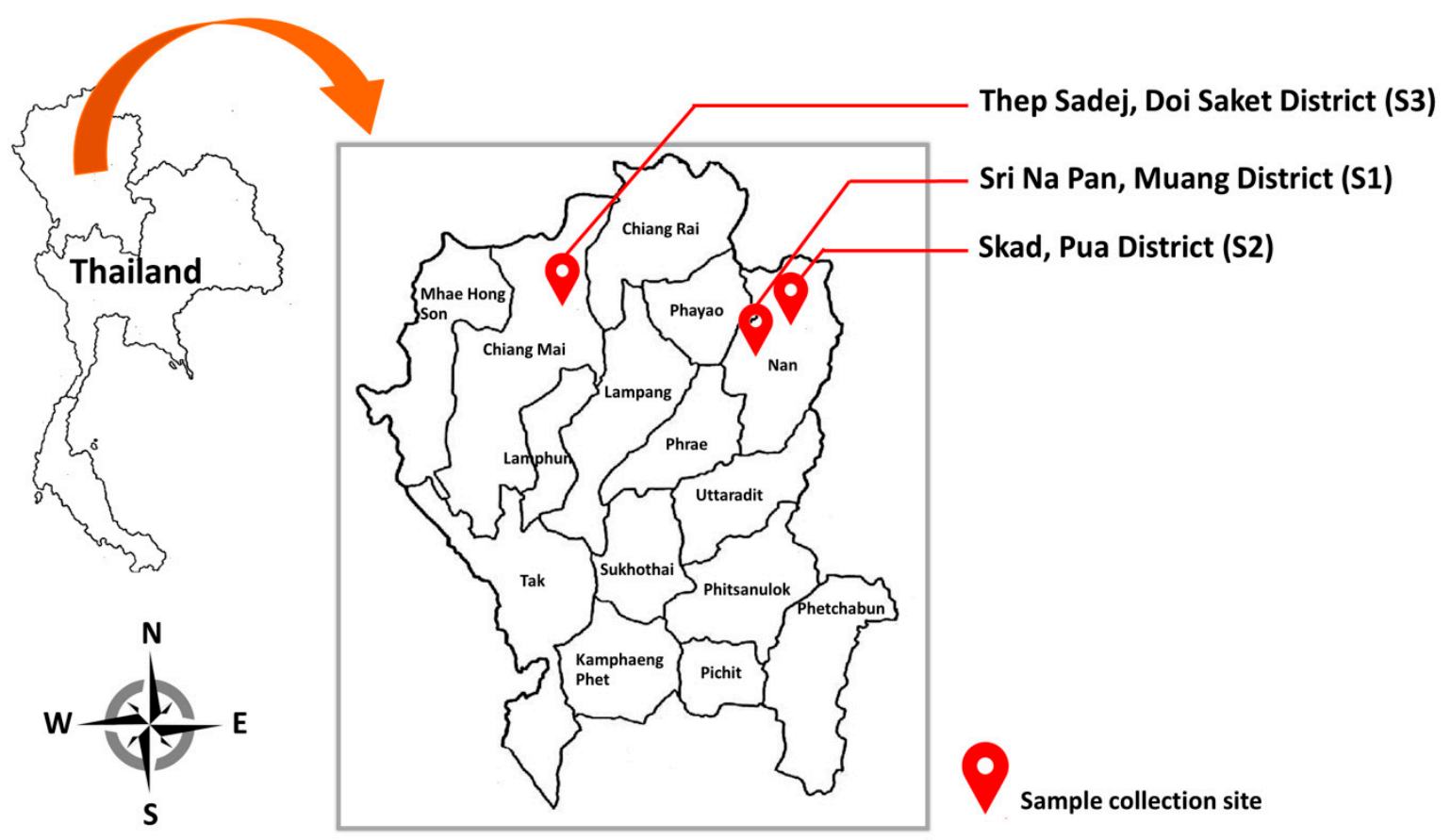

Figure 1. Map showing the location of sample collection sites.

Table 1. Location, soil type, $\mathrm{pH}$ value and electrical conductivity of collected soil samples.

\begin{tabular}{ccccc}
\hline Site & Location & Soil Type & pH Value & EC $(\mu \mathrm{S} / \mathbf{c m})$ \\
\hline S1 & Skad, Pua District, Nan Province & Sandy clay loam & 6.13 & 0.048 \\
S2 & Sri Na Pan, Muang District, Nan Province & Sandy clay loam & 6.06 & 0.046 \\
S3 & Thep Sadej, Doi Saket District, Chiang & Sandy clay loam & 6.54 & 0.049 \\
\hline
\end{tabular}

\subsection{Yeast Isolation}

Yeast strains were isolated using the enrichment method with some modifications. We placed 1 gram of the soil sample in $99 \mathrm{~mL}$ of yeast malt extract (YM) broth (Sigma-Aldrich, St. Louis, MO, USA) that had been combined with $50 \mathrm{mg} / \mathrm{L}$ of chloramphenicol in $250 \mathrm{~mL}$ Erlenmeyer flasks. Flasks were placed on an orbital shaker with shaking at $150 \mathrm{rpm}$ in the dark at $30{ }^{\circ} \mathrm{C}$ for $48 \mathrm{~h}$. After $48 \mathrm{~h}$ of incubation, the dilution spread plate method was employed with seven serial dilutions in $0.5 \% \mathrm{NaCl}$ solution. After dilution, $0.1 \mathrm{~mL}$ of suspension was spread on YM agar (Sigma-Aldrich, St. Louis, MO, USA) combined with $50 \mathrm{mg} / \mathrm{L}$ chloramphenicol. The plates were incubated at $30{ }^{\circ} \mathrm{C}$ for $48 \mathrm{~h}$. Different yeast colonies were selected based on relevant morphological characteristics. The individual colonies were re-grown at $30{ }^{\circ} \mathrm{C}$ on YM agar for purification. The pure strains were kept in $20 \%$ glycerol at $-80{ }^{\circ} \mathrm{C}$ and deposited in the Culture Collection of the Research Center of Microbial Diversity and Sustainable Utilization, Faculty of Science, Chiang Mai University, Thailand.

\subsection{Yeast Identification}

Each yeast strain was cultivated in $5 \mathrm{~mL}$ of $\mathrm{YM}$ broth in $18 \times 180 \mathrm{~mm}$ test tubes with shaking at $150 \mathrm{rpm}$ in the dark. After $48 \mathrm{~h}$, yeast cells were harvested by centrifugation and washed three times with sterile distilled water. Genomic DNA was extracted using a Fungal DNA Extraction Mini Kit (FAVORGEN, Ping-Tung, Taiwan). The D1/D2 region of the large subunit ribosomal RNA (LSU rRNA) gene was amplified by polymerase chain reactions (PCR) using NL1 and NL4 primers [30]. The amplification process was performed in a polymerase chain reaction (PCR) that consisted of an initial denaturation at $95^{\circ} \mathrm{C}$ for $5 \mathrm{~min}$, followed by 35 cycles of denaturation at $95^{\circ} \mathrm{C}$ for $30 \mathrm{~s}$, annealing at $52{ }^{\circ} \mathrm{C}$ for $45 \mathrm{~s}$, an extension at $72{ }^{\circ} \mathrm{C}$ for $1 \mathrm{~min}$ and $72{ }^{\circ} \mathrm{C}$ for $10 \mathrm{~min}$. PCR products were checked and 
then purified using a NucleoSpin Gel and PCR Clean-up Kit (Macherey-Nagel, Germany). The purified PCR products were directly sequenced at the 1st Base Company (Kembangan, Malaysia). The obtained sequences were compared with type strain sequences deposited in the Genbank database via BLAST (http://blast.ncbi.nlm.nih.gov, 25 June 2020) for the purposes of species identification. For phylogenetic analysis, multiple sequence alignment was carried out using MUSCLE [31]. Phylogenetic trees were constructed using maximum likelihood by RAxML v. 7.0.3 under the GTR+I+G model with 1000 bootstrap replicates $[32,33]$.

\subsection{Determination of Indole-3-Acetic Acid (IAA) Production}

Each yeast strain was grown in YM broth at $30^{\circ} \mathrm{C}$ and shaken at $125 \mathrm{rpm}$ for $48 \mathrm{~h}$ before being used. The cell density of each yeast strain was then adjusted using $0.5 \% \mathrm{NaCl}$ solution relative to the $0.5 \mathrm{McF}$ arland standard, which corresponded to $10^{8} \mathrm{CFU} / \mathrm{mL}$. The resulting solution was then used as an inoculum. One hundred microliters of yeast inoculum were added to $10 \mathrm{~mL}$ of YM broth that had been supplemented with $2 \mathrm{mg} / \mathrm{mL}$ L-tryptophan (L-trp; Sigma-Aldrich, Steinheim, Germany). These specimens were held at a pH of 6.0 in $18 \times 180 \mathrm{~mm}$ test tubes. Cultivation was performed in the dark at $30^{\circ} \mathrm{C}$ with shaking at $150 \mathrm{rpm}$ on an orbital shaker. After three days of incubation, the cultures were centrifuged at 11,000 rpm for $15 \mathrm{~min}$ to harvest the supernatant. The production of IAA of the tested strains was determined according to the colorimetric assay [28]. A pink to red color was considered positive for IAA production. Three replications were then made. The IAA in the supernatant was extracted and quantified with high performance liquid chromatography (HPLC) according to the method described by Kumla et al. [34].

\subsection{Determination of Siderophore Production}

The siderophore production was determined using chrome azurol S (CAS) agar [35]. One drop of yeast inoculum ( $5 \mu \mathrm{L}$ of $0.5 \mathrm{McF}$ arland standard) was dropped onto CAS agar. The inoculated plates were incubated at $30{ }^{\circ} \mathrm{C}$ in darkness for five days. The colonies producing a yellow, orange, purple or red zone were considered positive for siderophore production. Five replications were made.

\subsection{Determination of Ammonia Production}

A total of 100 microliters of yeast inoculum ( $0.5 \mathrm{McF}$ arland standard) was added to $10 \mathrm{~mL}$ of peptone water at a $\mathrm{pH}$ of $6.0 \mathrm{in} 18 \times 180 \mathrm{~mm}$ test tubes. Cultivation was performed in the dark at $30^{\circ} \mathrm{C}$ with shaking at $150 \mathrm{rpm}$ on an orbital shaker. After 5 days of incubation, ammonia production was detected using Nessler's reagent. The development of a yellow to brown color was indicative of a positive result for ammonia production [36]. Each treatment was performed in five replications.

\subsection{Determination of Mineral Solubilization Ability}

This experiment was carried out using basal medium ( $10.0 \mathrm{~g}$ glucose, $0.5 \mathrm{~g}(\mathrm{NH})_{4} \mathrm{SO}_{4}, 0.2 \mathrm{~g} \mathrm{NaCl}$, $0.1 \mathrm{~g} \mathrm{MgSO}_{4} \cdot 7 \mathrm{H}_{2} \mathrm{O}, 0.2 \mathrm{~g} \mathrm{KCl}, 0.5 \mathrm{~g}$ yeast extract, $0.002 \mathrm{~g} \mathrm{MnSO}_{4} \cdot \mathrm{H}_{2} \mathrm{O}$, and $15.0 \mathrm{~g}$ agar per liter of deionized water, $\mathrm{pH}$ 7.0) with the addition of non-soluble metal minerals including $\mathrm{AlPO}_{4}, \mathrm{Ca}_{3}\left(\mathrm{PO}_{4}\right)_{2}$, $\mathrm{CaCO}_{3}, \mathrm{CuCO}_{3} \cdot \mathrm{Cu}(\mathrm{OH})_{2}, \mathrm{CuO}, \mathrm{CoCO}_{3}, \mathrm{FePO}_{4}, \mathrm{MgCO}_{3}, \mathrm{MnO}, \mathrm{ZnCO}_{3}, \mathrm{ZnO}$, feldspar $\left(\mathrm{KAlSi}_{3} \mathrm{O}_{8}\right)$, and kaolin $\left(\mathrm{Al}_{2} \mathrm{Si}_{2} \mathrm{O}_{5}(\mathrm{OH})_{4}\right)$ to a desired final concentration of $0.1 \%$ according to the method described by Fomina et al. [37]. One drop of yeast inoculum ( $5 \mu \mathrm{L}$ of $0.5 \mathrm{McFarland}$ standard) was dropped onto the tested agar. The inoculated plates were incubated at $30^{\circ} \mathrm{C}$ in darkness for 5 days. The colony diameter and solubilization zone (halo zone) were measured. Solubilization index (SI) was calculated as the halo zone diameter divided by the yeast colony diameter [38]. SI values of less than 1.0, between 1.0 and 2.0, and more than 2.0 were considered indicative of low, medium and high solubilization activities, respectively [37]. Five replications were made in each treatment. 


\subsection{Determination of Extracellular Enzyme Production}

All yeast strains were investigated for extracellular enzyme production including endoglucanase, xylanase, pectinase, amylase, protease and lipase on agar plates. Enzyme production was reported as an enzyme activity index (EAI) and calculated as the ratio of the halo zone diameter and colony diameter [39]. One drop of yeast inoculum ( $5 \mu \mathrm{L}$ of $0.5 \mathrm{McFarland}$ standard) was dropped onto the tested agar. Five replications were made for each enzyme. Endoglucanase and xylanase productions were investigated on carboxymethyl cellulose (CMC) agar [40] and xylan agar [41,42], respectively. One drop of yeast inoculum $(5 \mu \mathrm{L})$ was dropped onto the tested media. The inoculated media were incubated at $30{ }^{\circ} \mathrm{C}$ in darkness for five days. The yeast colonies were rinsed with sterile distilled water, and the enzyme activity was determined by staining with $1 \%$ Congo red and was then destained with $1 \mathrm{M} \mathrm{NaCl}$ for $15 \mathrm{~min}$. The positive colonies produced a yellow zone of enzyme activity.

Pectinase and amylase productions were investigated on pectin agar [43] and starch agar [44], respectively. After inoculation, plates were incubated at $30{ }^{\circ} \mathrm{C}$ in darkness for 5 days. Pectinase and amylase activities were indicated by the development of a clear color change (yellow color) around or beneath the colonies after flooding the plate with $50 \mathrm{mM}$ potassium iodide-iodine solution.

Protease production was tested on skim milk-YNB agar [45], and lipase production was determined on the Sierra's agar [46]. After inoculation, plates were incubated at $30^{\circ} \mathrm{C}$ in darkness for 5 days. The presence of a clear zone around or beneath the colony indicated enzyme activity.

\section{Results}

\subsection{Yeast Isolation and Identification}

The results revealed that 11, 17 and 14 strains of the isolated yeast strains were obtained from Site 1 (Skad, Pua District, Nan Province), Site 2 (Sri Na Pan, Muang District, Nan Province) and Site 3 (Thep Sadej, Doi Saket District, Chiang Mai Province), respectively. A total of 42 strains were identified as belonging to 12 known yeast species and three unrecognized species (Table 2, Figures 2 and 3). It was found that 11 strains represented six species, namely Aureobasidium melanogenum, Kazachstania aquatic, Saturnispora diversa, Saturnispora sekii, Schwanniomyces pseudopolymorphus, and Wickerhamomyces anomalus belonged to the phylum Ascomycota. We identified 24 strains of six species, namely Apiotrichum scarabaeorum, Curvibasidium pallidicorallinum, Papiliotrema laurentii, Rhodosporidiobolus ruineniae, Trichosporon asahii and Trichosporon coremiiforme in the phylum Basidiomycota. Additionally, seven strains were categorized as previously unrecognized species belonging to the genera Galactomyces and Wickerhamomyces, and further study would be required for their identification.

\subsection{Determination of IAA Production}

Under culture conditions, all yeast strains were effectively able to grow. A total of 28 strains of six species (Ap. scarabaeorum, C. pallidicorallinum, P. laurentii, R. ruineniae, T. asahii and T. coremiiforme and one unrecognied species (Wickerhamomyces sp. 1) were positive for IAA production when tested by Salkowski's reagent, as indicated by the formation of pink and red colors. The identification of IAA was confirmed by HPLC. The analysis indicated the presence of IAA produced from the yeast strains, which corresponded to the authentic IAA standard with a retention time of $10.1 \mathrm{~min}$ and a maximum absorption of $279 \mathrm{~nm}$ according to Kumla et al. [34]. The amount of IAA was also quantified by HPLC and is shown in Table 3. The amount of IAA ranged from 2.12 to $37.32 \mathrm{mg} / \mathrm{L}$, which deepened according to the yeast strain. The highest amount of IAA was obtained from R. ruineniae SDBR-CMU-S1-03. 
Table 2. Identification of yeast strains obtained in this study based on analysis of the D1/D2 region of the large subunit ribosomal RNA (LSU rRNA) gene.

\begin{tabular}{|c|c|c|c|c|}
\hline Site & $\begin{array}{c}\text { Strain } \\
\text { SDBR-CMU }\end{array}$ & GenBank Number & Closeted Type Species/Similarity (\%) & Identification \\
\hline \multirow[t]{11}{*}{ S1 } & S1-01 & MT613405 & Trichosporon asahii CBS 2479/100 & T. asahii \\
\hline & S1-02 & MT613406 & Papiliotrema laurentii CBS 13999.87 & P. laurentii \\
\hline & S1-03 & MT613407 & Rhodosporidiobolus ruineniae CBS 5001/100 & R. ruineniae \\
\hline & S1-04 & MT623567 & Trichosporon asahii CBS 2479/100 & T. asahii \\
\hline & S1-05 & MT623565 & Rhodosporidiobolus ruineniae CBS 5001/100 & R. ruineniae \\
\hline & S1-06 & MT613408 & Wickerhamomyces anomalus CBS 5759/100 & W. anomalus \\
\hline & S1-07 & MT613409 & Trichosporon asahii CBS 2479/100 & T. asahii \\
\hline & S1-08 & MT623566 & Trichosporon asahii CBS 2479/100 & T. asahii \\
\hline & S1-09 & MT623568 & Rhodosporidiobolus ruineniae CBS 5001/100 & R. ruineniae \\
\hline & S1-10 & MT613410 & Aureobasidium melanogenum CBS 105.22/100 & A. melanogenum \\
\hline & S1-11 & MT613411 & $\begin{array}{c}\text { Wickerhamomyces xylosivorus NBRC } \\
111553 / 89.85\end{array}$ & Wickerhamomyces sp. 1 \\
\hline \multirow[t]{17}{*}{ S2 } & S2-01 & MT613683 & Rhodosporidiobolus ruineniae CBS 5001/100 & R. ruineniae \\
\hline & S2-02 & MT623569 & $\begin{array}{c}\text { Wickerhamomyces xylosivorus NBRC } \\
111553 / 89.85\end{array}$ & Wickerhamomyces sp. 1 \\
\hline & S2-03 & MT623575 & Trichosporon asahii CBS 2479/100 & T. asahii \\
\hline & S2-04 & MT613721 & Papiliotrema laurentii CBS 139/99.87 & P. laurentii \\
\hline & S2-05 & MT623576 & Rhodosporidiobolus ruineniae CBS 5001/100 & R. ruineniae \\
\hline & S2-06 & MT613722 & $\begin{array}{c}\text { Wickerhamomyces xylosivorus NBRC } \\
111553 / 89.85\end{array}$ & Wickerhamomyces sp. 1 \\
\hline & S2-07 & MT623572 & Aureobasidium melanogenum CBS 105.22/100 & A. melanogenum \\
\hline & S2-08 & MT623573 & Trichosporon asahii CBS 2479/100 & T. asahii \\
\hline & S2-09 & MT613858 & Curvibasidium pallidicorallinum CBS 9091/100 & C. pallidicorallinum \\
\hline & $\mathrm{S} 2-10$ & MT623570 & Wickerhamomyces anomalus CBS 5759/100 & W. anomalus \\
\hline & S2-11 & MT623574 & Rhodosporidiobolus ruineniae CBS 5001/100 & R. ruineniae \\
\hline & S2-12 & MT613867 & Curvibasidium pallidicorallinum CBS 9091/100 & C. pallidicorallinum \\
\hline & S2-13 & MT613870 & Kazachstania aquatica CBS 10102/100 & K. aquatica \\
\hline & S2-14 & MT623571 & Wickerhamomyces mori CBS 12678/90.97 & Wickerhamomyces sp. 2 \\
\hline & S2-15 & MT613872 & Kazachstania aquatica CBS 10102/100 & K. aquatica \\
\hline & S2-16 & MT613876 & Papiliotrema laurentii CBS 139/99.85 & P. laurentii \\
\hline & S2-17 & MT613875 & Wickerhamomyces mori CBS 12678/90.97 & Wickerhamomyces sp. 2 \\
\hline \multirow[t]{14}{*}{ S3 } & S3-01 & MT626064 & $\begin{array}{c}\text { Schwanniomyces pseudopolymorphus } \\
\text { CBS:2008/100 }\end{array}$ & S. pseudopolymorphus \\
\hline & S3-02 & MT626065 & Apiotrichum scarabaeorum CBS 5601/99.84 & Ap. scarabaeorum \\
\hline & S3-03 & MT632028 & $\begin{array}{c}\text { Schwanniomyces pseudopolymorphus } \\
\text { CBS:2008/100 }\end{array}$ & S. pseudopolymorphus \\
\hline & S3-04 & MT626066 & Saturnispora diversa NRRL Y-5713/100 & Sat. diversa \\
\hline & S3-05 & MT639220 & $\begin{array}{c}\text { Wickerhamomyces xylosivorus NBRC } \\
111553 / 89.85\end{array}$ & Wickerhamomyces sp. 1 \\
\hline & S3-06 & MT626068 & $\begin{array}{c}\text { Galactomyces pseudocandidum CBS } \\
820.71 / 97.87\end{array}$ & Galactomyces sp. \\
\hline & S3-07 & MT632029 & Papiliotrema laurentii CBS 139/99.86 & P. laurentii \\
\hline & S3-08 & MT626069 & Trichosporon coremiiforme CBS 2482/99.87 & T. coremiiforme \\
\hline & S3-09 & MT622026 & Trichosporon asahii CBS 2479/100 & T. asahii \\
\hline & S3-10 & MT626071 & Saturnispora sekii CBS 10931/100 & Sat. sekii \\
\hline & S3-11 & MT632027 & Rhodosporidiobolus ruineniae CBS 5001/100 & R. ruineniae \\
\hline & S3-12 & MT632031 & Trichosporon coremiiforme CBS 2482/99.87 & T. coremiiforme \\
\hline & S3-13 & MT632030 & Saturnispora sekii CBS 10931/100 & Sat. sekii \\
\hline & S3-14 & MT632025 & Trichosporon asahii CBS 2479/100 & T. asahii \\
\hline
\end{tabular}




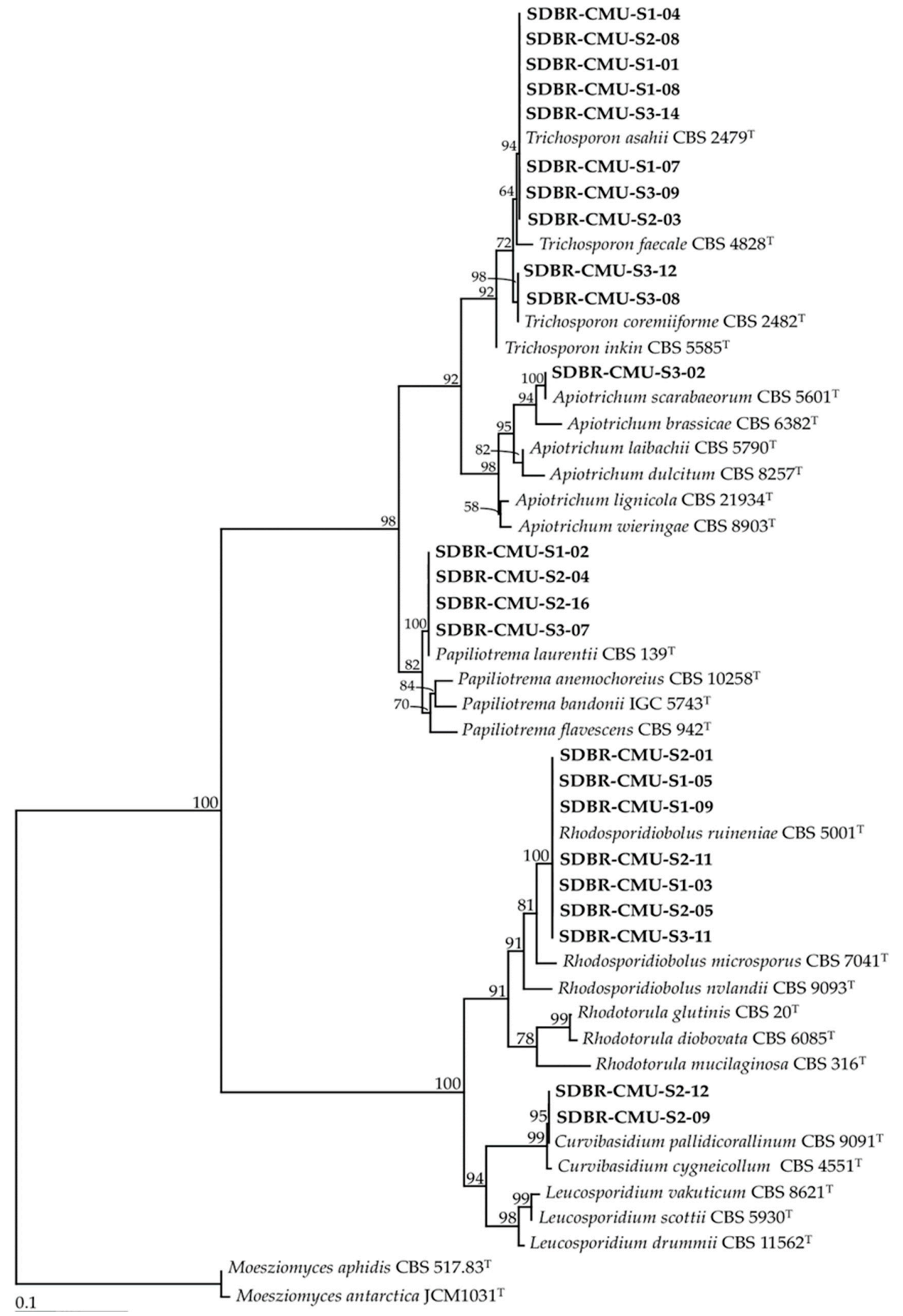

Figure 2. Phylogenetic tree of basidiomycetous yeast derived from maximum likelihood analysis of the D1/D2 region of the LSU rRNA gene. Rhodotorula mucilaginosa and $R$. diobovata were used as outgroup. Numbers above branches are the bootstrap statistics percentages. Branches with bootstrap values $\geq$ $50 \%$ are shown at each branch and the bar represent 0.1 substitutions per nucleotide position. The yeast strains obtained in this study are in bold. Superscription " $\mathrm{T}$ " means the type species. 


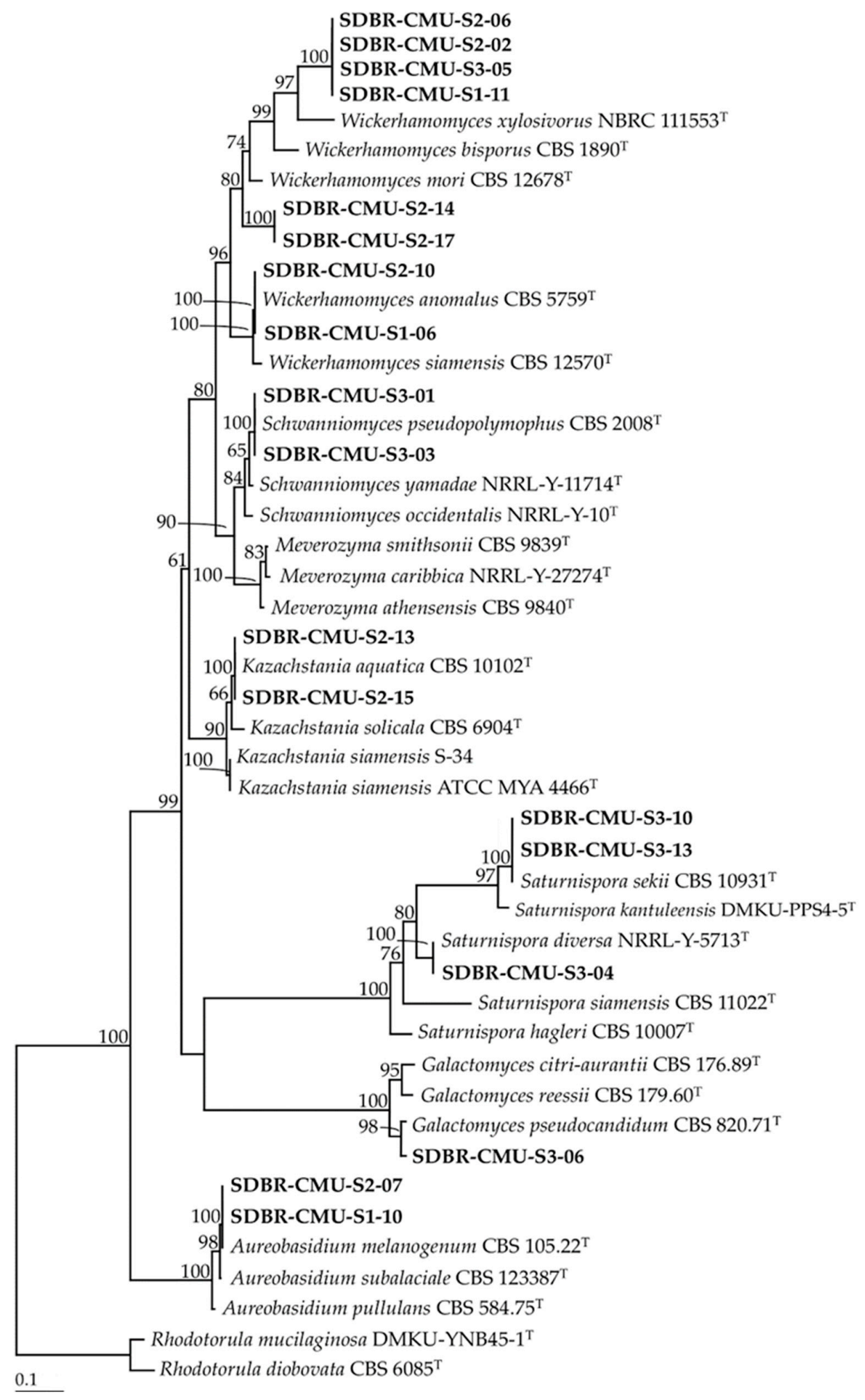

Figure 3. Phylogenetic tree of ascomycetous yeast derived from maximum likelihood analysis of the D1/D2 region of the LSU rRNA gene. Moesziomyces antarctica and M. aphidis were used as outgroup. Numbers above branches are the bootstrap statistics percentages. Branches with bootstrap values $\geq$ $50 \%$ are shown at each branch and the bar represent 0.1 substitutions per nucleotide position. The yeast strains obtained in this study are in bold. Superscription " $\mathrm{T}$ " means the type species. 
Table 3. Production of indole-3-acetic acid by yeast strains in this study.

\begin{tabular}{|c|c|c|}
\hline Yeast Species & Strain SDBR-CMU & Amount of IAA $(\mathrm{mg} / \mathrm{L})$ * \\
\hline \multirow[t]{8}{*}{ Trichosporon asahii } & S1-01 & $3.21 \pm 2.19$ \\
\hline & S1-04 & $3.65 \pm 1.34$ \\
\hline & S1-07 & $2.12 \pm 1.35$ \\
\hline & S1-08 & $4.21 \pm 1.87$ \\
\hline & S2-03 & $2.53 \pm 1.46$ \\
\hline & S2-08 & $5.02 \pm 2.05$ \\
\hline & S3-09 & $3.82 \pm 2.14$ \\
\hline & S3-14 & $2.35 \pm 0.92$ \\
\hline \multirow[t]{4}{*}{ Papiliotrema laurentii } & S1-02 & $2.35 \pm 1.97$ \\
\hline & $\mathrm{S} 2-04$ & $3.54 \pm 1.06$ \\
\hline & S2-16 & $2.78 \pm 1.53$ \\
\hline & S3-07 & $2.93 \pm 2.04$ \\
\hline \multirow[t]{7}{*}{ Rhodosporidiobolus ruineniae } & $\mathrm{S} 1-03$ & $37.32 \pm 3.05$ \\
\hline & S1-05 & $20.45 \pm 2.67$ \\
\hline & S1-09 & $18.38 \pm 1.28$ \\
\hline & S2-01 & $26.73 \pm 3.24$ \\
\hline & S2-05 & $17.45 \pm 2.03$ \\
\hline & $\mathrm{S} 2-11$ & $14.63 \pm 2.15$ \\
\hline & S3-11 & $23.45 \pm 3.04$ \\
\hline \multirow[t]{4}{*}{ Wickerhamomyces sp. 1} & S1-11 & $17.36 \pm 2.12$ \\
\hline & $\mathrm{S} 2-02$ & $12.45 \pm 3.16$ \\
\hline & S2-06 & $10.38 \pm 2 / 18$ \\
\hline & S3-05 & $16.63 \pm 1.96$ \\
\hline \multirow[t]{2}{*}{ Curvibasidium pallidicorallinum } & S2-09 & $8.61 \pm 1.37$ \\
\hline & S2-12 & $3.62 \pm 1.75$ \\
\hline Apiotrichum scarabaeorum & S3-02 & $4.24 \pm 1.48$ \\
\hline \multirow[t]{2}{*}{ Trichosporon coremiiforme } & S3-08 & $4.56 \pm 2.42$ \\
\hline & S3-12 & $3.52 \pm 1.87$ \\
\hline
\end{tabular}

${ }^{*}$ Data are means \pm standard deviation of three replicates.

\subsection{Determination of Siderophore and Ammonia Production}

Siderophore production was detected on CAS agar media. The results indicated that only eight yeast strains were positive for siderophore production by the formation of a pink zone around the colonies (Figure 4). These eight strains were identified to three known species that were named as P. laurentii (SDBR-CMU-S1-02, S2-04, S2-16 and S3-07), A. melanogenum (SDBR-CMU-S1-10) and Ap. scarabaeorum (SDBR-CMU-S3-02), and one recognized species named as Wickerhamomyces sp. 2 (SDBR-CMU-S2-14 and S2-17). In addition, all yeast strains were positive for ammonia production by the development of a yellow to brown color after Nessler's reagent was added to each culture.

\subsection{Determination of Mineral Solubilization Ability}

The ability of all yeast strains to solubilize insoluble minerals was determined by producing a solubilization zone (clear zone) around the colony on the agar containing each insoluble mineral. The results indicated that all yeast strains were not able to produce a solubilization zone in all tested insoluble minerals, except for $P$. laurentii and $W$. anomalus. These strains belonging to two species were able to solubilize the insoluble form of phosphate and zinc (Table 4, Figure 4). Four strains of P. laurentii could solubilize $\mathrm{Ca}_{3}\left(\mathrm{PO}_{4}\right)_{2}$ and $\mathrm{ZnO}$ at medium and high levels of activity, respectively. Two strains of $\mathrm{W}$. anomalus displayed a medium degree of activity in terms of the solubilization of $\mathrm{Ca}_{3}\left(\mathrm{PO}_{4}\right)_{2}, \mathrm{ZnO}$ and $\mathrm{ZnCO}_{3}$. 


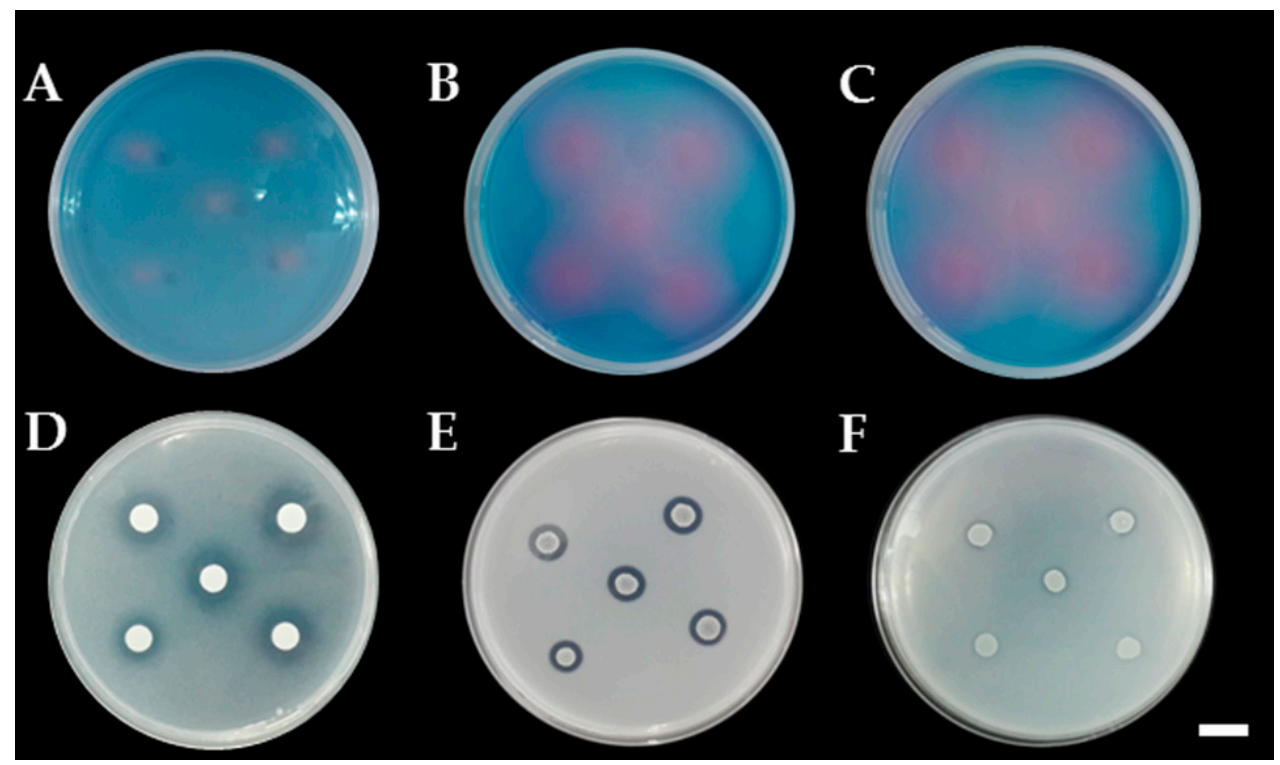

Figure 4. Color change zone on chrome azurol S (CAS) agar of siderophore production of P. laurentii SDBR-CMU-S1-02 (A), Wickerhamomyces sp. SDBR-CMU-S2-14 (B), and Ap. scarabaeorum SDBR-CMUS3-02 (C). (D-F); clear zone of minerals solubilization, $\mathrm{Ca}_{3}\left(\mathrm{PO}_{4}\right)_{2}$ solubilization by W. anomalus SDBRCMU-S1-06 (D), ZnCO 3 solubilization by W. anomalus SDBR-CMU-S1-06 (E), ZnO solubilization by W. anomalus SDBR-CMU-S1-06 (F). Scale bar $=10 \mathrm{~mm}$.

Table 4. Solubilization of insoluble minerals by yeast strains in this study.

\begin{tabular}{|c|c|c|c|c|}
\hline \multirow{2}{*}{ Yeast Species } & \multirow{2}{*}{$\begin{array}{c}\text { Strain } \\
\text { SDBR-CMU }\end{array}$} & \multicolumn{3}{|c|}{ Solubilization Index */Solubilization Activities } \\
\hline & & $\mathrm{Ca}_{3}\left(\mathrm{PO}_{4}\right)_{2}$ & $\mathrm{ZnO}$ & $\mathrm{ZnCO}_{3}$ \\
\hline \multirow{4}{*}{$\begin{array}{c}\text { Papiliotrema } \\
\text { laurentii }\end{array}$} & S1-02 & $1.32 \pm 0.94 /$ Medium & $2.13 \pm 0.92 / \mathrm{High}$ & - \\
\hline & S2-04 & $1.04 \pm 0.54 /$ Medium & $2.05 \pm 0.32 / \mathrm{High}$ & - \\
\hline & S2-16 & $1.26 \pm 0.72 /$ Medium & $2.08 \pm 0.24 / \mathrm{High}$ & - \\
\hline & S3-07 & $1.26 \pm 0.36 /$ Medium & $2.07 \pm 0.36 /$ High & - \\
\hline \multirow{2}{*}{$\begin{array}{c}\text { Wickerhamomyces } \\
\text { anomalus }\end{array}$} & S1-06 & $1.56 \pm 0.61 /$ Medium & $1.34 \pm 0.21 /$ Medium & $1.52 \pm 0.31 /$ Medium \\
\hline & S2-10 & $1.48 \pm 0.17 /$ Medium & $1.27 \pm 0.35 /$ Medium & $1.38 \pm 0.52 /$ Medium \\
\hline
\end{tabular}

\subsection{Determination of Extracellular Enzyme Production}

The ability of all yeast strains to produce extracellular enzymes was determined and the enzyme activity index is shown in Table 5 and Figure 5. The results indicate that the eight yeast strains of K. aquatica, P. laurentii and S. pseudopolymorphus produced amylase. Additionally, 23 strains belonging to five species (R. ruineniae, S. pseudopolymorphus, T. asahii, T. coremiiforme and W. anomalus) could produce endoglucanase. Lipase was produced by the 23 yeast strains of $R$. ruineniae, P. laurentii, T. asahii, T. coremiiforme and Sat. diversa. Pectinase production was observed in four of the strains of P. laurentii. Protease was produced by two strains of $W$. anomalus and four strains of P. laurentii. Lastly, 15 strains of A. melanogenum, R. ruineniae, P. laurentii and Ap. scarabaeorum, and one unrecognized species identified as Galactomyces sp., could produce xylanase. 
Table 5. Enzyme production of yeast strains in this study.

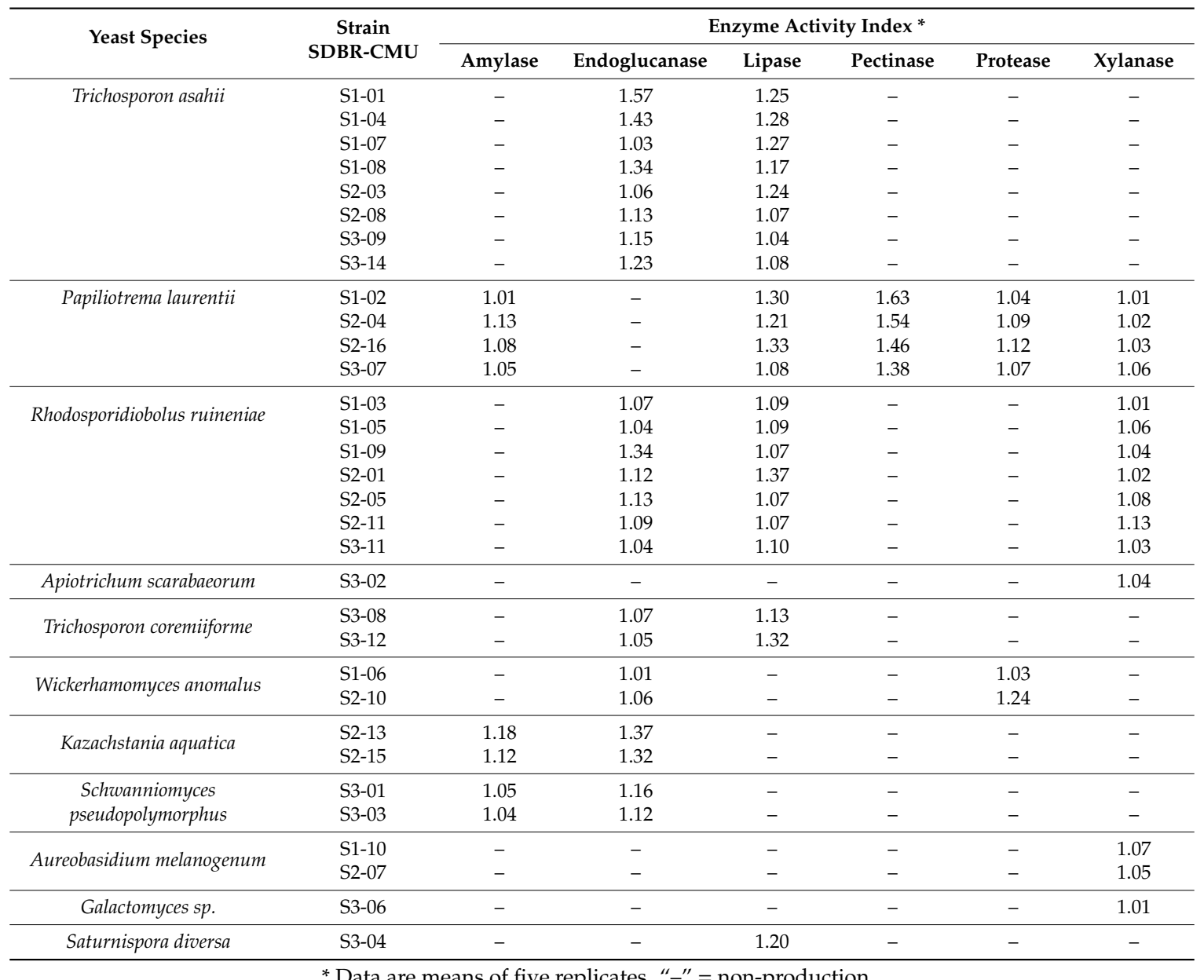

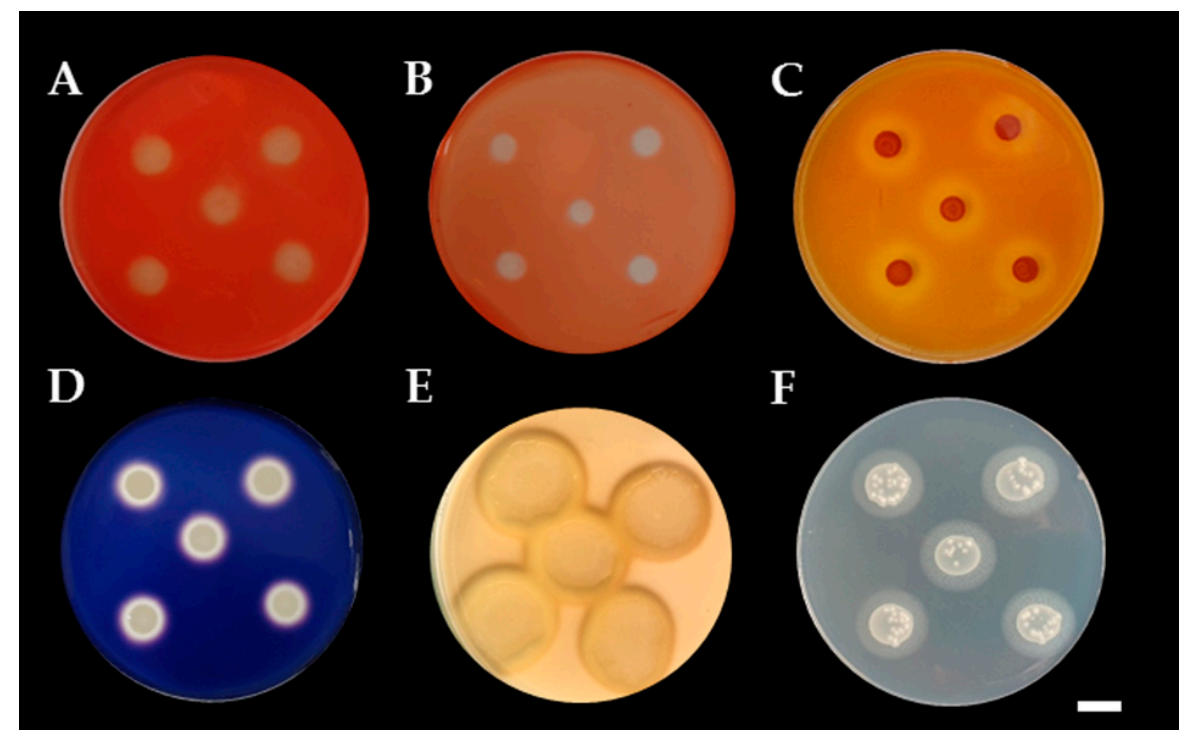

Figure 5. (A-F); Screening of extracellular enzyme production, endoglucanase production by T. asahii SDBR-CMU-S1-01 (A), xylanase production by P. laurentii SDBR-CMU-S1-02 (B), pectinase production P. laurentii SDBR-CMU-S1-02 (C), amylase production by P. laurentii SDBR-CMU-S2-04 (D), protease production by W. anomalus SDBR-CMU-S2-10 (E) and lipase production by T. asahii SDBR-CMU-S1-07 (F). Scale bar $=10 \mathrm{~mm}$. 


\section{Discussion}

Soil is the most favorable environment for microorganisms including yeast strains [24,25]. In this study, both ascomycetous and basidiomycetous yeasts were recovered from the soil samples of the Assam tea plant (C. sinensis var. assamica) that had been collected in northern Thailand using the enrichment isolation technique. These results were in accordance with the findings of previous studies which reported that ascomycetous and basidiomycetous yeast strains were recovered from various soil samples [24,47-49]. Many ascomycetous yeast strains in the genera Aureobasidium, Barnettozyma, Cyberlindnera, Kazachstania, Lipomyces and Schwanniomyces are known to be generally more abundant and are more frequently found in soil [24,50,51]. Apiotrichum, Cryptococcus, Papiliotrema, Rhodotorula and Trichosporon were also identified as the dominant form of basidiomycetous yeast in soil samples [24,50,52]. In addition, yeast communities in the soil are influenced by both abiotic and biotic factors including soil organic matter content, $\mathrm{pH}$, conductivity, temperature and the availability of water and macronutrients [52-54]. Among the 10 species identified in this study, A. melanogenum, P. laurentii, R. ruineniae, S. pseudopolymorphus, Sat. diversa, Sat. sekii, T. asahii, T. coremiiforme, Ap. scarabaeorum and W. anomalus are known to have been isolated from soil [28,52,53,55-57]. Interestingly, seven strains in the genera Galactomyces and Wickerhamomyces that were obtained in this study are representative of new potential species and will require further study.

In this study, certain plant growth promoting capabilities (the production of IAA, siderophore, ammonia and extracellular enzymes, and the solubilization of insoluble minerals) of all isolated yeast strains were investigated. IAA is a dominant type of auxin found in plants and is involved in certain specific plant growth responses identified as cell elongation, cell division, cell differentiation and root initiation $[58,59]$. The main precursor for IAA synthesis was L-trp [60]. IAA has been produced not only in plants, but also by certain microorganisms [60,61]. L-trp is present in root exudates and influences IAA production in microorganisms through only the Trp-dependent IAA biosynthetic pathway $[62,63]$. Previous studies have reported that yeast can produce IAA in the presence and absence of L-trp [26,27,64,65]. Our results revealed that 28 strains of six species (Ap. scarabaeorum C. pallidicorallinum, P. laurentii, R. ruineniae, T. asahii and T. coremiiforme) and one unrecognied species (Wickerhamomyces sp. 1) could produce IAA in liquid medium supplemented with L-trp with a supplemented amount of IAA ranging from 2.12 to $37.32 \mathrm{mg} / \mathrm{L}$. Our findings agreed with the results of a number of previous studies that found that the amount of IAA production from microorganisms (including bacteria, yeast and fungi) was less than $100 \mathrm{mg} / \mathrm{L} \mathrm{[66-68].} \mathrm{However,} \mathrm{the} \mathrm{amount} \mathrm{of} \mathrm{IAA}$ production obtained from yeast strains varied with different yeast species, and higher amounts of IAA production have been detected in some yeast strains. For example, Limtong et al. [69] found that Rhodosporidium fluviale DMKU-RK253 and Candida michaelii DMKU-RK343 could produce IAA at 565.1 and $259.0 \mathrm{mg} / \mathrm{L}$, respectively. Additionally, Rhodotorula paludigena DMKU-RP301 showed the highest IAA production at $364.1 \mathrm{mg} / \mathrm{L} \mathrm{[65].} \mathrm{Fu} \mathrm{et} \mathrm{al.} \mathrm{[26]} \mathrm{found} \mathrm{that} \mathrm{A.} \mathrm{pullulans} \mathrm{JYC104} \mathrm{and}$ Rh. paludigena JYC100 produced IAA at 610.63 and $400.59 \mathrm{mg} / \mathrm{L}$, respectively. Moreover, several previous studies demonstrated that IAA-producing yeast strains could increase the root length of plants $[23,26,64,70]$.

Most microorganisms produce siderophores as chelating agents for ferric ion. This not only supports plant growth but also indirectly inhibits plant pathogens by scavenging the available iron from the host environment [71-73]. In this study, A. melanogenum, P. laurentii, Ap. scarabaeorum and Wickerhamomyces sp. 2 were found to be positive for siderophore production. This result was supported by the findings of several previous studies which reported that some species of yeast in the genera Aureobasidium, Candida, Debaryomyces, Hanseniaspora, Holtermanniella, Lachancea, Meyerozyma, Pichia, Rhodotorula, Trichosporon and Wickerhamomyces could produce siderophores $[64,65,74]$. Ammonia production is one of the general characteristics of PGPMs [75]. Microbial production of ammonia potentially plays an important role in plant growth promotion via the availability of nitrogen $[75,76]$. The process of providing ammonia from microorganisms to the plant has been considered of vital importance. However, whether ammonia production is a common trait of yeast 
strains is unknown. In our study, all yeast strains possess ammonia-producing abilities. This result was similar to that of Fu et al. [26] who found that some yeast strains, namely A. pullulans, Galactomyces candidum, Hanseniaspora uvarum, Kazachstania jiainica, Meyerozyma caribbica, M. aphidis, P. laurentii and R. ruineniae, isolated from the rhizospheres of Drosera spatulata could produce ammonia.

Mineral-solubilizing microorganisms play a role in utilizing the available nutrition by enhancing their availability to plants through the solubilization and mineralization in the soil [77,78]. Mineral solubilization is influenced by the combined effect of a decrease in $\mathrm{pH}$ value and a decrease in organic acid production [77-79]. In this study, we evaluated the mineral-solubilizing ability of isolated yeast strains. The results indicated that only two yeast species, P. laurentii and W. anomalus, were able to solubilize the insoluble form of phosphate $\left(\mathrm{Ca}_{3}\left(\mathrm{PO}_{4}\right)_{2}\right)$, and zinc $(\mathrm{ZnO} \text { and } \mathrm{ZnCO})_{3}$. These results were similar to those of other previous studies which reported on the phosphate and zinc-solubilizing abilities of both yeast species [26,65,80-82]. Moreover, some species of yeast in the genera Aureobasidium, Barnettozyma, Candida, Holtermanniella, Lachancea, Pichia, Rhodotrula, Saccharomyces, Torulaspora have been recognized for their phosphate and zinc-solubilizing abilities [26,29,80-84]. Additionally, a number of previous studies have reported that the insoluble mineral solubilization ability of yeast cultures can vary depending on the type of mineral and yeast species as well as the particular yeast strain $[26,29,83,84]$.

The ability of yeast to produce extracellular enzymes, including amylase, endoglucanase, lipase, pectinase, protease and xylanase, was investigated in this study. It was found that the ability to produce enzymes was dependent upon the yeast species and strain, which is in accordance with the findings of several previous studies [26,28,29]. Another mechanism through which microorganisms inhibit plant pathogenic organisms is the production of cell wall-degrading enzymes. The cell wall-degrading enzymes, especially cellulase (endoglucanase, exoglucanase and $\beta$-glucosidase) and protease, can affect the structural integrity of the walls of the target pathogen, while indirectly promoting the growth of the host plant $[85,86]$. Some species of yeast in the genera Candida, Cryptococcus, Debaryomyces, Holtermaniella, Moesziomyces, Rhodotorula, Saccharomyces, Schwanniomyces and Trichosporon have been reported for cellulase and protease producers [26,84,87-90]. In our study, all strains of R. ruineniae, S. pseudopolymorphus, T. asahii, T. coremiiforme and W. anomalus produced endogulcanase. Notably, P. laurentii has been reported to produce endogulcanase [91], but none of the P. laurentii strains obtained in this study produced this enzyme. The protease production of P. laurentii and W. anomalus observed in this study has also been reported by previous studies $[26,84,85]$.

Our study found that the yeast strains belonging to P. laurentii and W. anomalus displayed the most promising plant growth promoting activities. Previous studies reported that P. laurentii and $W$. anomalus could be isolated from soil samples, and they displayed multifarious plant growth promoting activity [26,28,69,81,91]. In 2016, Moller et al. [92] reported that the L. laurentii strain CAB 91 isolated from the rhizosphere soil of the blue lupin (Lupinus angustifolius) could enhance the growth of the blue lupin and improve its nutritional physiology. Though these species were reported as a PGPM, they are considered opportunistic human pathogens [93,94]. Therefore, the strains of PGPMs may represent a potential threat to humans, animals and the environment. Thus, more information is required regarding the toxicity of these strains, and clinical tests in the laboratory should be conducted for the purposes of safety before they are used $[95,96]$.

\section{Conclusions}

Currently of particular relevance is the search for microorganisms that display multifunctional biological activity. In this study, yeast strains isolated from the Assam tea soil collected from plantations located in northern Thailand have shown multifarious plant growth promoting traits. Our results indicate the potential application of these yeast strains, especially P. laurentii and W. anomalus, in various agricultural areas and specifically for the development of biofertilizers. However, some yeast strains may represent a potential threat to humans, animals or the health of plants. Therefore, laboratory assays of their toxicity are necessary, and clinical tests are needed in future studies to fully understand 
the profile of these yeast strains. Important and vital research must be done on these yeast strains before their application can be approved. Additionally, field trials should be conducted in the future, particularly with regard to the management and safety of these yeast strains.

Author Contributions: Conceptualization: J.K., S.N., N.S., S.L.; methodology: J.K., S.N., N.S.; software: J.K., N.S.; validation: J.K., S.L.; formal analysis: J.K., S.N., N.S.; investigation: J.K., N.S.; resources: J.K., N.S., S.L.; data curation: J.K., N.S.; writing—original draft: J.K., S.N.; writing—review and editing: J.K., S.N., N.S., S.L.; supervision: S.L. All authors have read and agreed to the published version of the manuscript.

Funding: The authors gratefully acknowledge the financial support provided from Center of Excellence on Biodiversity (BDC), The Office of The Higher Education Commission, (BDC-PG4-161008), Research Center for Multidisciplinary Approaches to Miang, Chiang Mai University and partially supported by Chiang Mai University, Thailand.

Acknowledgments: The authors are grateful to Russell Kirk Hollis for his kind help in the English correction of this manuscript and Chartchai Kanongnuch for his excellent field assistance.

Conflicts of Interest: The authors declare no competing or financial interests.

\section{References}

1. Wight, W.; Baruwa, P.K. What is tea? Nature 1957, 179, 506-507. [CrossRef]

2. Ming, T.L. Monograph of the Genus Camellia; Yunnan Science and Technology Press: Kunming, China, 2000; 352p.

3. Chen, J.; Wang, P.S.; Xia, Y.M.; Xu, M.; Pei, S.J. Genetic diversity and differentiation of Camellia sinensis L. (cultivated tea) and its wild relatives in Yunnan province of China, revealed by morphology, biochemistry and allozyme studies. Genet. Resour. Crop. Evol. 2005, 52, 41-52. [CrossRef]

4. Korsamphan, C.; Boonma, W.; Sringarm, K. Diversity of local tea on highland of northern Thailand. J. Agric. 2010, 26, 93-99.

5. Khanongnuch, C.; Unban, K.; Kanpeiengjai, A.; Saenjum, C. Recent research advances and ethno-botanical history of miang, a traditional fermented tea (Camellia sinensis var. assamica) of northern Thailand. J. Ethn. Foods 2017, 4, 135-144. [CrossRef]

6. Kawakami, M.; Chairote, G.; Kobayashi, A. Flavor constituents of pickled tea, miang, in Thailand. Agric. Biol. Chem. 1987, 51, 1683-1687.

7. Phromrukachat, S.; Tiengburanatum, N.; Meechui, J. Assessment of active ingredients in pickled tea. Asian J. Food Agro-Ind. 2010, 3, 312-318.

8. Lin, W.; Lin, M.; Zhou, H.; Wu, H.; Li, Z.; Lin, W. The effects of chemical and organic fertilizer usage on rhizosphere soil in tea orchards. PLoS ONE 2019, 14, e0217018. [CrossRef]

9. Gao, G. Experiment studies on the hygienics of AsBaCdPb in tea. Chin. J. Food. Hygiene. 2001, 13, 12-14.

10. Li, Y.; Li, Z.; Arafat, Y.; Lin, W.; Jiang, Y.; Weng, B.; Lin, W. Characterizing rhizosphere microbial communities in long-term monoculture tea orchards by fatty acid profiles and substrate utilization. Eur. J. Soil Biol. 2017, 81, 48-54. [CrossRef]

11. Maghanga, J.K.; Kituyi, J.L.; Kisinyo, P.O.; Ng'etich, W.K. Impact of nitrogen fertilizer applications on surface water nitrate levels within a kenyan tea plantation. J. Chem. 2012, 1, 196516. [CrossRef]

12. Ruan, J.; Gerendas, J.; Haerdter, R.; Sattelmacher, B. Effect of root zone $\mathrm{pH}$ and form and concentration of nitrogen on accumulation of quality-related components in green tea. J. Sci. Food Agric. 2007, 87, 1505-1516. [CrossRef]

13. Wang, Z.; Geng, Y.; Liang, T. Optimization of reduced chemical fertilizer use in tea gardens based on the assessment of related environmental and economic benefits. Sci. Total. Environ. 2020, 713, 136439. [CrossRef] [PubMed]

14. Martinez-Viveros, O.; Jorquera, M.A.; Crowlet, D.E.; Gajardo, G.; Mora, M.L. Mechanisms and practical considerations involved in plant growth promotion by rhizobacteria. J. Soil Sci. Plant Nutr. 2010, 10, 239-319. [CrossRef]

15. Arora, N.K. Agricultural sustainability and food security. Environ. Sustain. 2018, 1, 217-219. [CrossRef]

16. Tamenkovic, S.; Beskoski, V.; Karabegovic, I.; Lazic, M.; Nikolic, N. Microbial fertilizers: A comprehensive review of current findings and future perspectives. Span. J. Agric. Res. 2018, 16, e09R01. [CrossRef] 
17. Naik, K.; Mishra, S.; Srichandan, H.; Singh, P.K.; Sarangi, K. Plant growth promoting microbes: Potential link to sustainable agriculture and environment. Biocatal. Agric. Biotechnol. 2019, 21, 101326. [CrossRef]

18. Mishra, J.; Singh, R.; Arora, N.K. Plant growth-promoting microbes: Diverse roles in agriculture and environmental sustainability. In Probiotics and Plant Health; Kumar, V., Kumar, M., Sharma, S., Prasad, R., Eds.; Springer: Singapore, 2017; pp. 71-111.

19. Abhilash, P.C.; Dubey, R.K.; Tripathi, V.; Gupta, V.K.; Singh, H.B. Plant growth-promoting microorganisms for environmental sustainability. Trends Biotechnol. 2016, 34, 847-850. [CrossRef]

20. Rilling, J.; Acuña, J.; Nannipieri, P.; Cassan, F.; Maruyama, F.; Jorquera, M. Current opinion and perspectives on the methods for tracking and monitoring plant growth-promoting bacteria. Soil Biol. Biochem. 2019, 130, 205-219. [CrossRef]

21. Wagi, S.; Ahmed, A. Phyllospheric plant growth promoting bacteria. J. Bacteriol. Mycol. 2017, 5, $215-216$.

22. Gupta, H.; Saini, R.V.; Pagadala, V.; Kumar, N.; Sharma, D.K.; Saini, A.K. Analysis of plant growth promoting potential of endophytes isolated from Echinacea purpurea and Lonicera japonica. J. Soil. Sci Plant Nutr. 2016, 16, 588-597. [CrossRef]

23. Ignatova, L.V.; Brazhnikova, Y.V.; Berzhanova, R.Z.; Mukasheva, T.D. Plant growth-promoting and antifungal activity of yeasts from dark chestnut soil. Microbiol. Res. 2015, 175, 78-83. [CrossRef] [PubMed]

24. Yurkov, A.M. Yeasts of the soil - obscure but precious. Yeast 2018, 35, 369-378. [CrossRef] [PubMed]

25. Botha, A. The importance and ecology of yeasts in soil. Soil Biol. Biochem. 2011, 43, 1-8. [CrossRef]

26. Fu, S.F.; Sun, P.F.; Lu, H.Y.; Wei, J.Y.; Xiao, H.S.; Fang, W.T.; Cheng, B.Y.; Chou, J.Y. Plant growth-promoting traits of yeasts isolated from the phyllosphere and rhizosphere of Drosera spatulata Lab. Fungal Biol. 2016, 120, 433-448. [CrossRef]

27. Limtong, S.; Koowadjanakul, N. Yeasts from phylloplane and their capability to produce indole-3-acetic acid. World J. Microbiol. Biotechnol. 2012, 28, 3323-3335. [CrossRef]

28. Jaiboon, K.; Lertwattanasakul, N.; Limtong, P.; Limtong, S. Yeasts from peat in a tropical peat swamp forest in Thailand and their ability to produce ethanol, indole-3-acetic acid and extracellular enzymes. Mycol. Prog. 2016, 15, 755-770. [CrossRef]

29. Amprayn, K.; Rose, M.Y.; Kecskes, M.; Pereg, L.; Nguyen, H.T.; Kennedy, I.R. Plant growth promoting characteristics of soil yeast (Candida tropicalis HY) and its effectiveness for promoting rice growth. Appl. Soil Ecol. 2012, 61, 295-299. [CrossRef]

30. Stielow, J.B.; Levesque, C.A.; Seifert, K.A.; Meyer, W.; Lriny, L.; Smits, D.; Renfurm, R.; Verkely, G.J.M.; Groenewald, M.; Chaduli, D.; et al. One fungus, which genes? Development and assessment of universal primers for potential secondary fungal DNA barcodes. Persoonia 2015, 35, 242-263. [CrossRef]

31. Edgar, R.C. MUSCLE: Multiple sequence alignment with high accuracy and high throughput. Nucleic Acids Res. 2004, 32, 1792-1797. [CrossRef]

32. Stamatakis, A. RAxML-VI-HPC: Maximum likelihood based phylogenetic analyses with thousands of taxa and mixed models. Bioinformatics 2006, 22, 2688-2690. [CrossRef]

33. Felsenstein, J. Confidence intervals on phylogenetics: An approach using bootstrap. Evolution 1985, 39, 783-791. [CrossRef] [PubMed]

34. Kumla, J.; Suwannarach, N.; Bussaban, B.; Matsui, K.; Lumyong, S. Indole-3-acetic acid production, solubilization of insoluble metal minerals and metal tolerance of some sclerodermatoid fungi collected from northern Thailand. Ann. Microbial. 2014, 64, 707-720. [CrossRef]

35. Louden, B.C.; Haarmann, D.; Lynne, A.M. Use of blue agar CAS Assay for siderophore detection. J. Microbiol. Biol. Educ. 2011, 12, 51-53. [CrossRef] [PubMed]

36. Cappuccino, J.G.; Sherman, N. Microbiology: A Laboratory Manual, 6th ed.; Pearson Education: London, UK, 2002.

37. Fomina, M.A.; Alexander, I.J.; Colpaert, J.V.; Gadd, G.M. Solubilization of toxic metal minerals and metal tolerance of mycorrhizal fungi. Soil Biol. Biochem. 2005, 37, 851-866. [CrossRef]

38. Nosrati, R.; Owlia, P.; Saderi, H.; Rasooli, I.; Malboobi, M.A. Phosphate solubilization characteristics of efficient nitrogen fixing soil Azotobacter strains. Iran J. Microbiol. 2014, 6, $285-295$.

39. Hankin, L.; Anagnostakis, S.L. The use of solid media for the detection of enzyme production by fungi. Mycologia 1975, 67, 567-607. [CrossRef]

40. Kasana, R.C.; Salwan, R.; Dhar, H.; Dutt, S.; Gulati, A. A rapid and easy method for the detection of microbial cellulases on agar plates using Gram's iodine. Curr. Microbiol. 2008, 57, 503-507. [CrossRef] 
41. Lopes, F.; Motta, F.; Andrade, C.C.P.; Rodrigues, M.I.; Maugeri-filho, F. Thermo-stable xylanases from non-conventional yeasts. J. Microbiol. Biochem. Technol. 2011, 3, 36-42.

42. Otero, D.M.; Cadaval, C.L.; Teixeira, L.M.; Rosa, C.A.; Sanzo, A.V.L.; Kalil, S.J. Screening of yeasts capable of producing cellulase-free xylanase. Afr. J. Biotechnol. 2015, 14, 1961-1969. [CrossRef]

43. Haile, M.; Kang, W.H. Isolation, identification, and characterization of pectinolytic yeasts for starter culture in coffee fermentation. Microorganism 2019, 7, 401. [CrossRef]

44. Yalçin, T.; Çorbac1, C. Isolation and characterization of amylase producing yeasts and improvement of amylase production. Turk. J. Biochem. 2013, 38, 101-108. [CrossRef]

45. Charoenchai, C.; Fleet, G.H.; Henschke, P.A.; Todd, B.E.N.T. Screening of non-Saccharomyces wine yeasts for the presence of extracellular hydrolytic enzymes. Aust. J. Grape Wine Res. 1997, 3, 2-8. [CrossRef]

46. Elegado, F.; Legaspi, C.L.; Paet, J.M.; Querubin, F.; Tolentino, J.E.; Vilela, J.; Paguio, A.; Maloles, J.; Zarate, J. Screening, identification and optimization of extracellular lipase production of yeast (Cryptococus flavescens) isolated from a tree canopy fern in the Mount Makiling Forest Reserve, Philippines. AIP Conf. Proc. 2019, 2155, 020029.

47. Moreira, G.A.M.; do Vale, H.M.M. Occurrence of yeast species in soils under native and modified vegetation in an iron mining area. Rev. Bras. Cienc. Solo 2018, 42, e0170375. [CrossRef]

48. Mohamed, H.M.; El-Homosy, R.F.; Abd-Ellatef, A.H.; Salh, F.M.; Hussein, M.Y. Identification of yeast strains isolated from agricultural soils for releasing potassium-bearing minerals. Geomicrobiol. J. 2017, 34, 261-266. [CrossRef]

49. Diaz, P.E.; Aranda, C.; Martinez, O.; Godoy, R.; Gonzales, A.; Valenzuela, E. Characterization of yeast in hapludands soil with biotechnological potential. J. Soil Sci. Plant Nutr. 2017, 17, 948-965. [CrossRef]

50. Liu, X.Z.; Wang, Q.M.; Göker, M.; Groenewald, M.; Kachalkin, A.V.; Lumbsch, H.T.; Bai, F.Y. Towards an integrated phylogenetic classification of the Tremellomycetes. Stud. Mycol. 2015, 81, 85-147. [CrossRef]

51. Vadkertiová, R.; Dudášová, H.; Balaščáková, M. Yeasts in agricultural and managed soils. In Yeasts in Natural Ecosystems: Ecology; Buzzini, P., Lachance, M.A., Yurkov, A.M., Eds.; Springer: Heidelberg, Germany, 2017; pp. 117-144.

52. Yurkov, A.M. Yeasts in forest soils. In Yeasts in Natural Ecosystems: Ecology; Buzzini, P., Lachance, M.A., Yurkov, A.M., Eds.; Springer: Heidelberg, Germany, 2017; pp. 87-116.

53. Slavikova, E.; Vandkertiova, R. The diversity of yeast in the agricultural soil. J. Basic Microbiol. 2003, 43, 430-436. [CrossRef]

54. Birkhofer, K.; Schöning, I.; Alt, F.; Herold, N.; Klarner, B.; Maraun, M.; Schrumpf, M. General relationships between abiotic soil properties and soil biota across spatial scales and different land-use types. PLoS ONE 2012, 7, e43292. [CrossRef]

55. Glushakova, A.; Maksimova1, I.; Morozova, A.; Kachalkin, A. Distribution features of yeasts in soils of South Vietnam (case study of the biogeocenoses of the National Park Cát Tiên). IOP Conf. Ser. Earth Environ. Sci. 2019, 368, 012012. [CrossRef]

56. van Nieuwenhuijzen, E.J.; Houbraken, J.A.; Meijer, M.; Adan, O.C.; Samson, R.A. Aureobasidium melanogenum: A native of dark biofinishes on oil treated wood. Anton Leeuw. 2016, 109, 661-683. [CrossRef] [PubMed]

57. Haq, I.; Nawaz, A.; Manzoor, Z.; Rehman, A.; Mukhtar, H.; Aftab, M.; Arshad, Y. A new multi-stress resistant Wickerhamomyces anomalus: Isolation, identification and bioethanol fermentation potential. Rev. Mex. Ing. Quim. 2019, 18, 841-849. [CrossRef]

58. Quint, M.; Gray, W.M. Auxin signaling. Curr. Opin. Plant Biol. 2006, 9, 448-453. [CrossRef] [PubMed]

59. Zhao, Y. Auxin biosynthesis and its role in plant development. Annu. Rev. Plant Biol. 2010, 61, 49-64. [CrossRef] [PubMed]

60. Spaepen, S.; Vanderleyden, J. Auxin and plant-microbe interactions. Cold Spring Harb. Perspect. Biol. 2011, 3, a001438. [CrossRef]

61. Spaepen, S.; Vanderleyden, J.; Remans, R. Indole-3-acetic acid in microbial and microorganism-plant signaling. FEMS Microbiol. Rev. 2007, 31, 425-448. [CrossRef]

62. Niemi, K.; Vuorinen, T.; Ernstsen, A.; Haggman, H. Ectomycorrhizal fungi and exogenous auxins influence root and mycorrhiza formation of Scots pine hypocotyl cuttings in vitro. Tree Physiol. 2002, 22, 1231-1239. [CrossRef]

63. Kravchenko, L.V.; Azarova, T.S.; Makarova, N.M.; Tikhonovich, I.A. The effect of tryptophan present in plant root exudates on the phytostimulating activity of rhizobacteria. Microbiology 2004, 73, 156-158. [CrossRef] 
64. Sun, P.F.; Fang, W.T.; Shin, L.Y.; Wei, J.Y.; Fu, S.F.; Chou, J.Y. Indole-3-acetic acid-producing yeasts in the phyllosphere of the carnivorous plant Drosera indica L. PLoS ONE 2014, 9, 1-12. [CrossRef]

65. Nutaratat, P.; Srisuk, N.; Arunrattiyakorn, P.; Limtong, S. Plant growth-promoting traits of epiphytic and endophytic yeasts isolated from rice and sugar cane leaves in Thailand. Fungal Biol. 2014, 118, 683-694. [CrossRef]

66. Tsavkelova, E.A.; Cherdyntseva, T.A.; Botina, S.G.; Netrusov, A.I. Bacteria associated with orchid roots and microbial production of auxin. Microbiol. Res. 2007, 162, 69-76. [CrossRef] [PubMed]

67. Vitorino, L.C.; Silva, F.G.; Soares, M.A.; Souchie, E.L.; Costa, A.C.; Lima, W.C. Solubilization of calcium and iron phosphate and in vitro production of indole acetic acid by endophytic isolates of Hyptis marrubioides Epling (Lamiaceae). Int. Res. J. Biotechnol. 2012, 3, 47-54.

68. Chutima, R.; Lumyong, S. Production of indole-3-acetic acid by Thai native orchid-associated fungi. Symbiosis 2014, 56, 35-44. [CrossRef]

69. Limtong, S.; Kaewwichian, R.; Yongmanitchai, W.; Kawasaki, H. Diversity of culturable yeasts in phylloplane of sugarcane in Thailand and their capability to produce indole-3-acetic acid. World. J. Microbiol. Biotechnol. 2014, 30, 1785-1796. [CrossRef]

70. Nassar, A.H.; El-Tarabily, K.A.; Sivasithamparam, K. Promotion of plant growth by an auxin-producing isolate of the yeast Williopsis saturnus endophytic in maize (Zea mays L.) roots. Biol. Fertil. Soils 2005, 42, 97-108. [CrossRef]

71. Ahmed, E.; Holmstrom, S.J.M. Siderophores in environmental research: Roles and applications. Microb. Biotechnol. 2014, 7, 196-208. [CrossRef]

72. D’Onofrio, A.; Crawford, J.M.; Stewart, E.J.; Witt, K.; Gavrish, E.; Epstein, S.; Clardy, J.; Lewis, K. Siderophores from neighboring organisms promote the growth of uncultured bacteria. Chem. Biol. 2010, 17, 254-264.

73. Saha, R.; Saha, N.; Donofrio, R.S.; Bestervelt, L.L. Microbial siderophores: A mini review. J. Basic Microbiol. 2013, 53, 301-317. [CrossRef]

74. Thanh, V.N.; van Dyk, M.S.; Wingfield, M.J. Debaryomyces mycophilus sp. nov., a siderophore-dependent yeast isolated from woodlice. FEMS Yeast Res. 2002, 2, 415-427.

75. Mpanga, I.K.; Nkebiwe, P.M.; Kuhlmann, M.; Cozzolino, V.; Piccolo, A.; Geistlinger, J.; Berger, N.; Ludewig, U.; Neumann, G. The form of $\mathrm{N}$ supply determines plant growth promotion by P-solubilizing microorganisms in maize. Microorganisms 2019, 7, 38. [CrossRef]

76. Bartelme, R.P.; Oyserman, B.O.; Blom, J.E.; Sepulveda-Villet, O.J.; Newton, R.J. Stripping away the soil: Plant growth promoting microbiology opportunities in aquaponics. Front. Microbiol. 2018, 9, 8. [CrossRef] [PubMed]

77. Gadd, G.M. Metals, minerals and microbes: Geomicrobiology and bioremediation. Microbiology 2010, 156, 609-645. [CrossRef] [PubMed]

78. Mapelli, F.; Marasco, R.; Balloi, A.; Rolli, E.; Cappitelli, F.; Daffonchio, D.; Borin, S. Mineral-microbe interactions: Biotechnological potential of bioweathering. J. Biotechnol. 2012, 157, 473-481. [CrossRef] [PubMed]

79. Alori, E.T.; Glick, B.R.; Babalola, O.O. Microbial phosphorus solubilization and its potential for use in sustainable agriculture. Front. Microbiol. 2017, 8, 971. [CrossRef] [PubMed]

80. Mohamed, H.M.; Metwally, A.K. Effect of combined inoculation of Rhizobium with soil yeasts on nodulation, growth and yield of common bean (Phaseolus vulgaris L.) under field condition. Am. J. Plant Nutr. Fert. Technol. 2014, 4, 1-10. [CrossRef]

81. Into, P.; Khunnamwong, P.; Jindamoragot, S.; Am-in, S.; Intanoo, W.; Limtong, S. Yeast associated with rice phylloplane and their contribution to control of rice sheath blight disease. Microorganisms 2020, 8, 362. [CrossRef]

82. Gizaw, B.; Tsegay, Z.; Tefera, G.; Aynalem, E. Phosphate solubilizing yeast isolated and characterized from teff rhizosphere soil collected from gojam; Ethiopia. J. Bacteriol. Mycol. Open Access 2017, 5, 218-223. [CrossRef]

83. Mestre, M.C.; Fontenla, S.; Bruzone, M.C.; Fernández, N.V.; Dames, J. Detection of plant growth enhancing features in psychrotolerant yeasts from Patagonia (Argentina). J. Basic Microbiol. 2016, 56, 1098-1106. [CrossRef]

84. Fernandez-San, M.A.; Farran, I.; Larraya, L.; Ancin, M.; Arregui, L.M.; Veramendi, J. Plant growth-promoting traits of yeasts isolated from Spanish vineyards: Benefits for seedling development. Microbiol. Res. 2020, 237, 1-16. [CrossRef]

85. Jadhv, H.P.; Sayyed, R.Z. Hydrolytic enzymes of rhizospheric microbes in crop protection. Cell Sci. Rep. 2016, $3,135-136$. 
86. Whipps, J.M. Microbial interactions and biocontrol in the rhizosphere. J. Exp. Bot. 2001, 52, 487-511. [CrossRef] [PubMed]

87. Carrasco, M.; Villarreal, P.; Barahona, S.; Alcaíno, J.; Cifuentes, V.; Baeza, M. Screening and characterization of amylase and cellulase activities in psychrotolerant yeasts. BMC. Microbiol. 2016, 16, 1-9. [CrossRef] [PubMed]

88. Giese, E.C.; Dussán, K.J.; Pierozzi, M.; Chandel, A.K.; Pagnocca, F.C.; Da Silva, S.S. Cellulase production by Trichosporon laibachii. Orbital Electron. J. Chem. 2017, 4, 271-278. [CrossRef]

89. Adelabu, B.; Kareem, S.O.; Adeogun, A.I.; Wakil, S.M. Optimization of cellulase enzyme from sorghum straw by yeasts isolated from plant feeding-termite Zonocerus variegatus. Food. Biosci. 2019, 7, 81-101.

90. Escribano, R.; González-Arenzana, L.; Garijo, P.; Berlanas, C.; López-Alfaro, I.; López, R.; Gutie'rrez, A.R.; Santamaría, P. Screening of enzymatic activities within different enological non-Saccharomyces yeasts. J. Food Sci. Technol. 2017, 54, 1555-1564. [CrossRef] [PubMed]

91. Gomes, F.C.; Safar, S.V.; Marques, A.R.; Medeiros, A.O.; Santos, A.R.; Carvalho, C.; Lachance, M.A.; Sampaio, J.P.; Rosa, C.A. The diversity and extracellular enzymatic activities of yeasts isolated from water tanks of Vriesea minarum, an endangered bromeliad species in Brazil, and the description of Occultifur brasiliensis f.a., sp. nov. Anton. Leeuw. 2015, 107, 597-611. [CrossRef]

92. Moller, L.; Kessler, K.D.; Steyn, A.; Valentine, A.J. The role of Cryptococcus laurentii and mycorrhizal fungi in the nutritional physiology of Lupinus angustifolius L. hosting $\mathrm{N}_{2}$-fixing nodules. Plant Soil 2016, 409, 345-360. [CrossRef]

93. Yilmaz-Semerci, S.; Demirel, G.; Tastekin, A. Wickerhamomyces anomalus blood stream infection in a term newborn with pneumonia. Turk. J. Pediatr. Dis. 2017, 59, 349-351. [CrossRef]

94. Molina-Leyva, A.; Ruiz-Carrascosa, J.C.; Leyva-Garcia, A.; Husein-Elanmed, H. Cutaneous Cryptococcus laurentii infection in an immunocompetent child. Int. J. Infect. Dis. 2013, 17, 1232-1233. [CrossRef]

95. Vilchez, J.I.; Navas, A.; Gonzalez-Lopez, J.; Acros, S.C.; Manzanera, M. Biosafety test for plant growth-promoting bacteria: Proposed environmental and human safety index (EHSI) protocol. Front. Microbiol. 2015, 6, 1514. [CrossRef]

96. Sundh, I.; Hökeberg, M.; Levenfors, J.J.; Nilsson, A.I. Safety assessment of biocontrol and plant growth-promoting pseudomonads useful in crop production. Ann. Appl. Biol. 2011, 159, 291-301. [CrossRef]

(C) 2020 by the authors. Licensee MDPI, Basel, Switzerland. This article is an open access article distributed under the terms and conditions of the Creative Commons Attribution (CC BY) license (http://creativecommons.org/licenses/by/4.0/). 